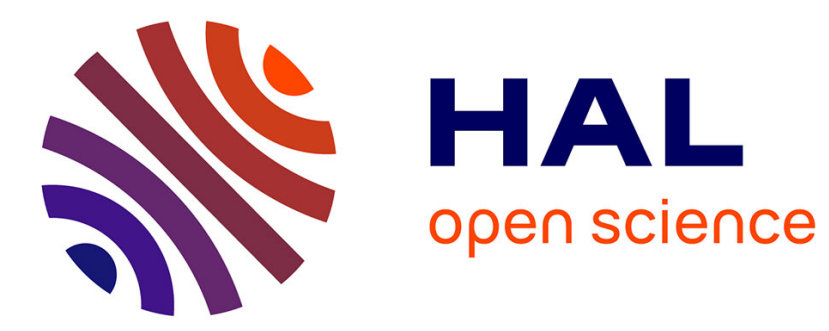

\title{
Investigation of a New Topology of Hybrid-Excited Flux-Switching Machine with Static Global Winding: Experiments and Modeling
}

Agathe Dupas, Sami Hlioui, Emmanuel Hoang, Mohamed Gabsi, Michel Lecrivain

\section{To cite this version:}

Agathe Dupas, Sami Hlioui, Emmanuel Hoang, Mohamed Gabsi, Michel Lecrivain. Investigation of a New Topology of Hybrid-Excited Flux-Switching Machine with Static Global Winding: Experiments and Modeling. IEEE Transactions on Industry Applications, 2015, 10.1109/TIA.2015.2497305 . hal01233372

\section{HAL Id: hal-01233372 \\ https://hal.science/hal-01233372}

Submitted on 25 Nov 2015

HAL is a multi-disciplinary open access archive for the deposit and dissemination of scientific research documents, whether they are published or not. The documents may come from teaching and research institutions in France or abroad, or from public or private research centers.
L'archive ouverte pluridisciplinaire HAL, est destinée au dépôt et à la diffusion de documents scientifiques de niveau recherche, publiés ou non, émanant des établissements d'enseignement et de recherche français ou étrangers, des laboratoires publics ou privés. 


\title{
Investigation of a New Topology of Hybrid-Excited Flux-Switching Machine with Static Global Winding: Experiments and Modeling
}

\author{
Agathe Dupas, Sami Hlioui, Emmanuel Hoang, Mohamed Gabsi and Michel Lecrivain \\ SATIE, CNRS, ENS Cachan \\ CNAM, Universud \\ 61, av President Wilson, F-94230 Cachan, France \\ adupas@satie.ens-cachan.fr
}

\begin{abstract}
This paper presents a new structure for a hybrid excitation, flux-switching synchronous machine. The particularity of this machine is its global excitation winding component that creates a 3D excitation flux path to control the global air gap flux. A 3D finite element analysis and a comparison with experimental results are both provided. This model makes it possible to: show the excitation flux path, explore the fluxregulation capability of a new structure, and identify the influence of material characteristics. The experimental performance of this machine in a DC generator is presented and compared with simulation output.
\end{abstract}

Index Terms-BH-curve, Diode Bridge Rectifier, FluxSwitching, Hybrid excitation machine, Measurements, Synchronous alternator, 3D-FEA

TABLE I

NOMENCLATURE

\begin{tabular}{|c||c|}
\hline FEA & Finite-Element Analysis. \\
\hline PM & Permanent Magnet. \\
\hline HEM & Hybrid Excited Machine. \\
\hline HEFSM & Hybrid Excited Flux-Switching Machine. \\
\hline DBR & Diode Bridge Rectifier. \\
\hline$\delta_{e x c}$ & Excitation current density. \\
\hline$\delta_{c c}$ & Short-circuit current density. \\
\hline$I_{c c}$ & Short-circuit current. \\
\hline EMF & Electromotive force. \\
\hline
\end{tabular}

\section{INTRODUCTION}

Hybrid Excited Machines combine the advantages of both wound-field excitation machines and permanent-magnet excited machines, with on the one hand electric excitation offering control of the magnetic field by controlling the excitation current and on the other a permanent magnet benefiting from high-energy density. Adding an excitation source however can complicate the structure.

Various hybrid excited topologies have been proposed in the literature and some authors have presented an overview of the different structures, e.g. [1][2]. This introduction will focus on the path taken by the magnetic flux, which allows us to distinguish two categories. The first comprises machines whose flux can be represented in a plane (a so-called "2D topology"). The second category includes machines whose flux lies both in the plane and perpendicular to the plane (hence a "3D topology"). This paper will work with a "3D topology".

The hybrid flux-switching (HEFSM, Tab.I) machine presented in [3], as derived from the flux-switching machine introduced by Rauch in [4], has a "2D topology" and features many optimizations since the original structure. Z.Q. Zhu [5] provided a complete review of various flux-switching structures and optimizations proposed in the literature.

Due to a salient passive rotor, the hybrid excited, fluxswitching permanent magnet machines exhibit high robustness and high torque density thanks to permanent magnets located on the stator. A review in [6] presents some hybrid excited, flux-switching machines with the topology shown in [7] ; these incorporate iron flux bridges in order to improve the effectiveness of field coil excitation. The new topology discussed in this article is a hybrid, flux-switching machine derived from [9], and its "3D-topology" differs from the initial "2D-topology".

Some hybrid-excitation machine topologies give rise to magnetic fluxes that cannot be represented in a plane. It becomes more complicated to classify existing topologies than the "2D-topologies" since adding a dimension multiplies the intentions of designers and multiple structures wind up being proposed. A number of structures however can still be distinguished. First of all, some machines combine two synchronous designs, one a permanent magnet synchronous machine the other containing windings. For example, the machines presented in [8]-[16] are indeed combinations of two synchronous configurations. Flux-concentrating machines, like in [17], are also included herein. The permanent magnets are located inside the rotor. Due to the flux-convergence effect, the air gap flux density of the machine is high.

The literature contains relatively few studies of hybrid excited, flux-switching permanent magnet machines with a 3D flux path. One such device is an axial Flux-Switching, Hybrid Excitation Synchronous Machine and is described in [18].

In this study, a new hybrid excitation, flux-switching machine is being presented. The main feature of this device is its global winding hybrid excitation with claw poles. This solution has been explored in order to reduce the copper mass and 
TABLE II

PROTOTYPE MACHINE SPECIFICATIONS

\begin{tabular}{|c||c|}
\hline Number of phases & 3 \\
\hline Number of stator slots & 12 \\
\hline Number of rotor teeth & 10 \\
\hline External stator radius & $100 \mathrm{~mm}$ \\
\hline External rotor radius & $45.5 \mathrm{~mm}$ \\
\hline Air gap & $0.25 \mathrm{~mm}$ \\
\hline Active axial length & $30 \mathrm{~mm}$ \\
\hline Number of turns per phase & 184 \\
\hline
\end{tabular}

TABLE III

MATERIALS

\begin{tabular}{|c||c|}
\hline Rotor & FeSi (laminated sheets) \\
\hline Stator & FeSi (laminated sheets) \\
\hline Stator Yokes & XC18 (NF: A35-551: 1986) \\
\hline Permanent magnets & NdFeB \\
\hline
\end{tabular}

increase excitation winding efficiency. One of the most widely used alternators in automotive applications is a claw pole alternator whose claws are located on the rotor. The prototype introduced in this article is based on the same principle yet with claws located on the stator, which allows its rotor to be passive in rotating at higher speeds without slip-rings or brushes. Furthermore, the advantages of the double excitation are cumulative. The article will first describe the structure and operating principles of this new hybrid excitation, fluxswitching machine. The second part will explore the no-load flux linkage and the back-electromotive force on a no-load using a 3D finite element analysis; the results of this analysis will then be compared with measurement data. The no-load flux linkage investigation serves to highlight: the influence of the stacking factor, the B-H curve definition, and the permanent magnet residual induction value $\left(B_{r}\right)$. Moreover, the load testing of this machine will be displayed. Short-circuit currents will be calculated and measured in order to determine the output power capability while operating in generator mode.

\section{HYBRID EXCITED FLUX-SWITCHING PERMANENT MAGNET PROTOTYPE}

Fig.1 shows the proposed 12-slot and 10-pole machine composed of $\mathrm{NdFeB}$ permanent magnets, an excitation winding and armature windings; the pertinent specifications are listed in Tab.II and Tab.III. This machine is flux-switching, hence the rotor is composed of ten salient poles without a permanent magnet (PM) or windings.

The stator can be divided into two parts. The first is composed of armature coils, permanent magnets and laminated sheets. The armature windings themselves consist of twelve windings located around teeth and the PM. The magnetic structure displays axial symmetry; this structure can be modeled in two dimensions and the flux path can be utilized without claws, as depicted in Fig.2. This figure indicates the flux-switching principle, with both the negative and positive maximum flux linkages occurring when a rotor pole is roughly

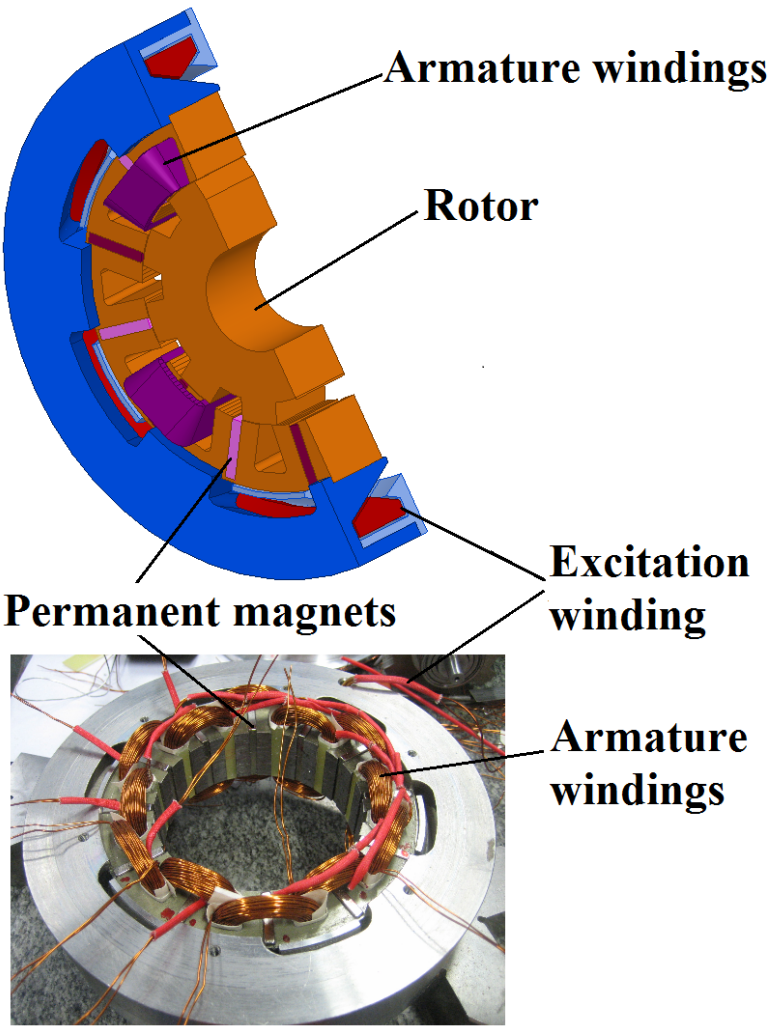

Fig. 1. 3D model and photograph of the Hybrid Excited, Flux-Switching Machine

aligned with one of the stator teeth. Some flux paths created by permanent magnets are actually short-circuited in the yoke, as shown in Fig.3. Without a claw pole structure, the maximum no-load flux linkage for a single coil equals $350 \mu \mathrm{Wb}$, whereas with a claw pole structure at an excitation current density $\left(\delta_{e x c}\right)$ equal to $0 \mathrm{~A} / \mathrm{mm}^{2}$, the maximum no-load flux linkage for one coil equals $204 \mu \mathrm{Wb}$ (some $40 \%$ of all flux paths are short-circuited in the yoke).

The "2D-structure" has been is derived from the hybrid excited, flux-switching machine presented in [9][20]. The main difference between these two machines lies in the hybrid excitation circuit. In [9], the excitation windings are composed of 12 windings and positioned on the permanent magnets

The second part of the stator is composed of a global wound inductor separated from the first part, which serves to avoid end-winding. An end-winding introduces copper losses and produces no flux linkage, whereas with a global winding all the "copper" is used for producing flux. Each stator yoke, which maintains the winding, is composed of six claws and made from solid iron materials. Fig.4 and Fig.5 show the excitation circuit. The DC current in the excitation winding is independently controllable, and the pertinent control circuit is exhibited in Fig.4.

The flux path created by the DC-excitation winding and without a PM is a 3D path and has been represented in Fig.6. As this figure reveals, the flux paths generated by the winding pass by one claw and return by the next claw. Fig.7 shows 
flux paths with permanent magnets and excitation windings. According to this configuration, the permanent magnet flux path and excitation winding flux path are opposite, thus the no-load flux linkage decreases.

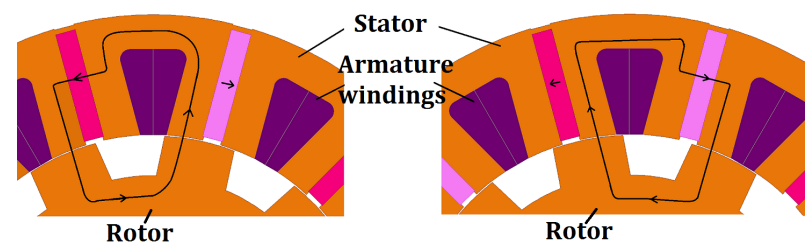

Fig. 2. First part of the stator: 2D flux paths utilized

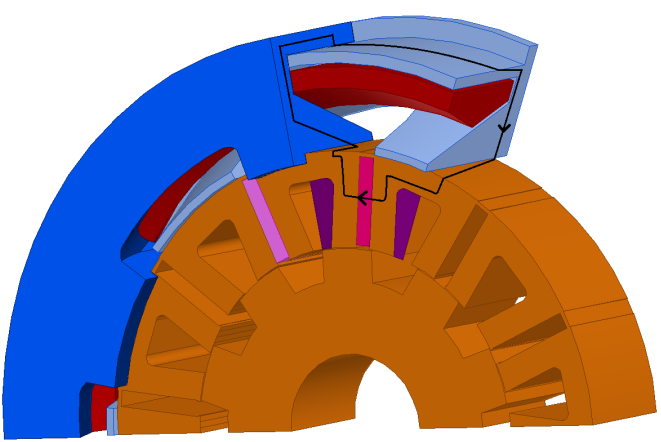

Fig. 3. First part of the stator: 3D flux paths utilized with claws

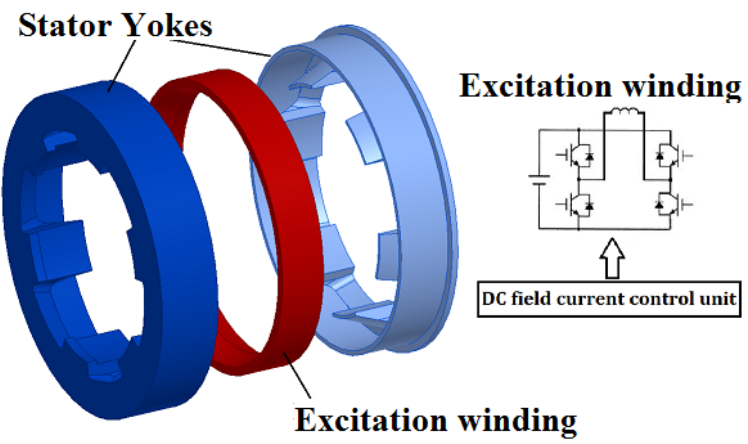

Fig. 4. Second part of the stator: Excitation circuit composed of two armatures and one winding, plus the control circuit

\section{3D Finite-ELEMENT ANALYSIS AND EXPERIMENTAL VALIDATION: NO-LOAD TESTS}

To validate the operating principle of this new structure and evaluate the potential of this concept, a prototype and simulations have been run. In this part, the operating principle on a no-load will be explored and measurements compared with 3D finite element analysis (FEA). The 3D finite element model was chosen since it takes the saturation effect into account and observes the influence of material definitions or the lamination effect. Two major difficulties of FE modeling consist of: reducing computation time without deteriorating

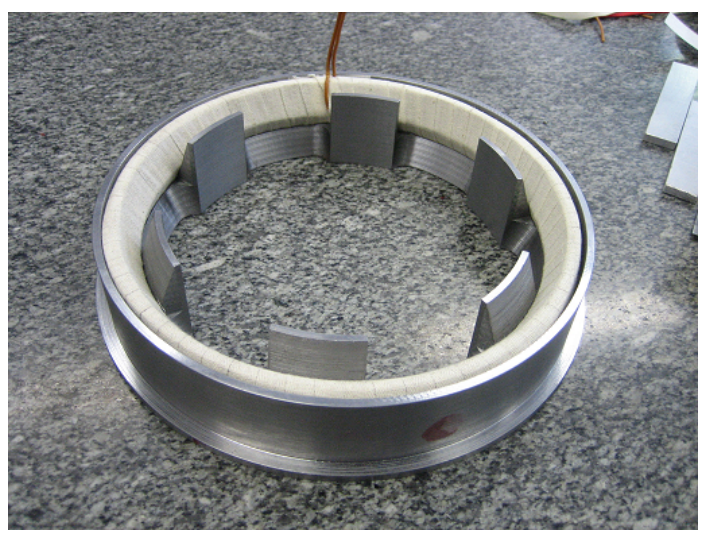

Fig. 5. Prototype: One half of claw pole stator yoke

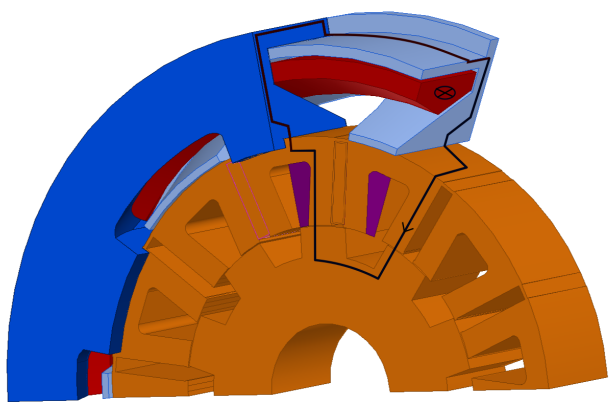

Fig. 6. Machine model without permanent magnets: 3D flux paths

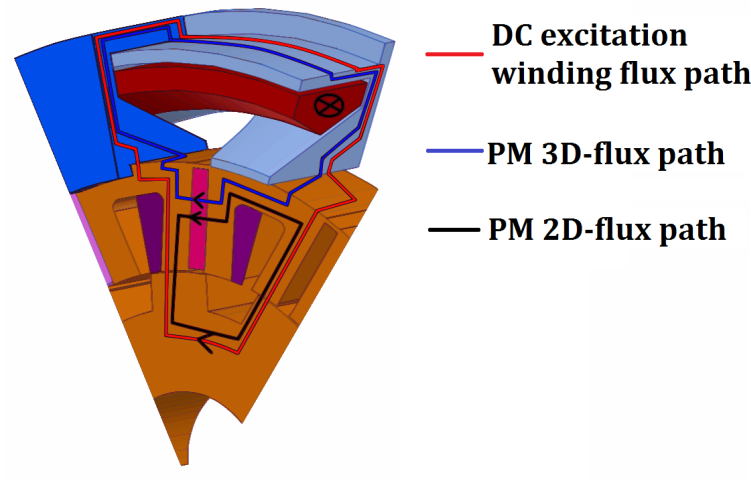

Fig. 7. Machine model with permanent magnets and excitation windings: 3D flux paths

model precision, and defining a realistic constitutive relation for the material. To avoid this second difficulty, our model results were compared to experimental measurements. The meshing offered a compromise between accuracy and computation time. Fig. 8 depicts the 3D finite element mesh of the studied machine. Different mesh sizes were compared in order to identify the mesh configuration that yields consistent results with respect to experimental measurements, yet without excessive computation times. The final model was composed of 365,888 tetrahedron elements. All 3D FEA were performed 
with the ANSYS Maxwell Software. The solver formulation is based on a current vector potential in conductors and a scalar potential over the entire field domain. The models employed were all supplied by current. A finite-element model of the half machine has been made by considering symmetry in order to reduce computation time. The half model was composed of 163,737 tetrahedron elements and provides the same results as presented in this paper with computation time divided by around two

In this part, for no-load test, the experimental test bench used is shown in Fig.9. As the prime mover of HEFSM, a $5.5-\mathrm{kW}$ induction motor was used.
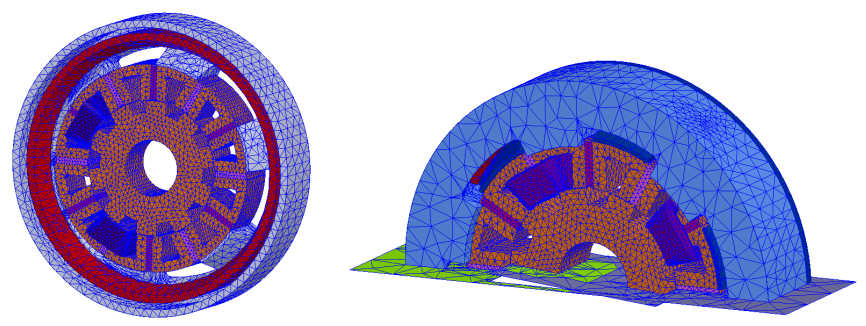

Fig. 8. FEA: View of the meshing configuration

\section{A. No-load flux linkage}

The first intrinsic machine characteristic observed was the no-load flux linkage, along with the influence of hybrid excitation on flux. The main advantage of hybrid excitation is, like with wound excitation for a synchronous machine, the flux regulation capability. In Fig.10, the no-load flux linkage can be viewed as a function of excitation current density. Thanks to the excitation current, the air gap magnetic field may be adjusted, as the no-load flux linkage per turn per slot ranges from $180 \mu W b$ to $380 \mu W b$. Fig.10 reveals that the maximum flux is reached for $\delta_{e x c}=9 \mathrm{~A} / \mathrm{mm}^{2}$. The flux decreases for $\delta_{e x c} \geq 9 \mathrm{~A} / \mathrm{mm}^{2}$, with this decrease being due to magnetic saturation phenomena in the stator. The saturation is located on stator teeth, as shown in Fig. 11.

The no-load flux linkage is explored through measurements, and this knowledge can then be used to readjust the finite element model. The influence of three parameters on no-load flux is investigated, namely: the $\mathrm{BH}$ curve of $\mathrm{FeSi}$ sheets, permanent magnet remanence, and the stacking factor.

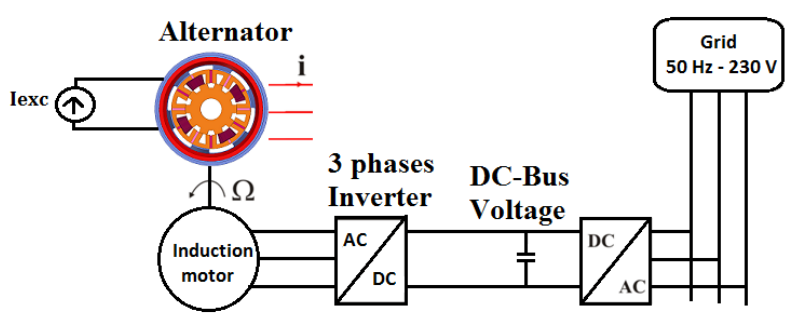

Fig. 9. Experimental test bench: No-load flux linkage and EMF measurements

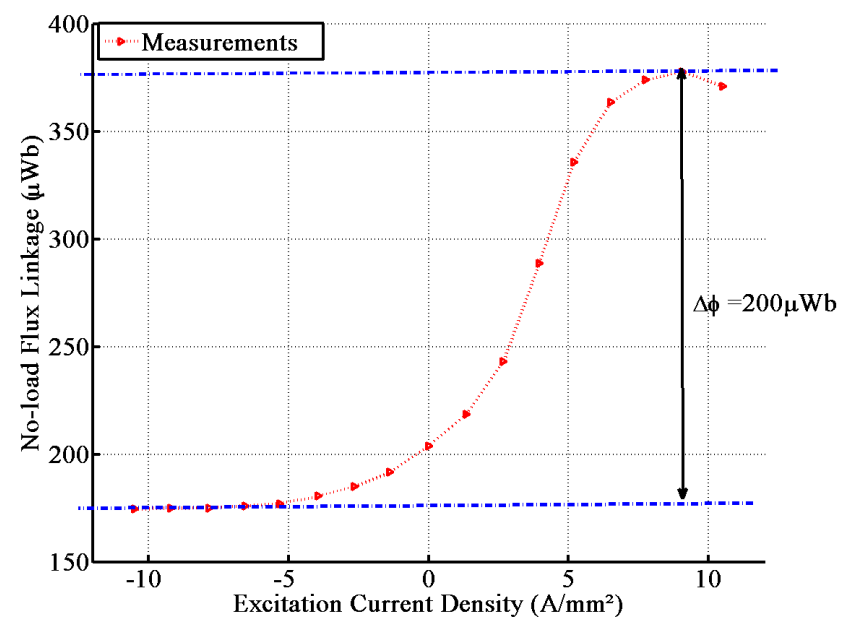

Fig. 10. Measurements: Evolution of no-load flux linkage vs. excitation current density per turn per slot
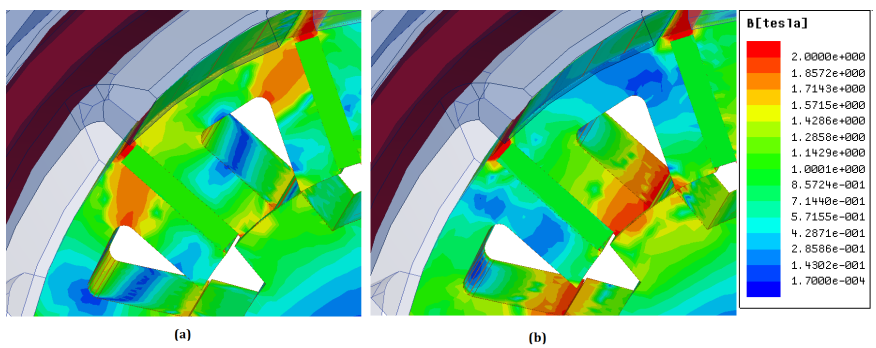

Fig. 11. FEA: Magnetic flux density distribution (a) $\delta_{e x c}=0 \mathrm{~A} / \mathrm{mm}^{2}$ (b) $\delta_{\text {exc }}=6 \mathrm{~A} / \mathrm{mm}^{2}$

a) Material definitions: The 3D finite element model allows determining the influence of material definition on the no-load flux. A comparison between two material definitions will be drawn first. The laminated parts of the stator and rotor are produced using $\mathrm{FeSi}$ sheets, which are defined by means of a B-H curve. Two curves are used, and the no-load flux linkage is calculated for both curves. The first curve, $\mathrm{BH}(1)$, is acquired with a permeameter in the laboratory. The permeameter yields a B-field for higher $\mathrm{H}$-field values than with an Epstein frame. The B-field is measured for an H-field between $200 A / m$ and $80,000 A / m$. The values for $H \leq 200 \mathrm{~A} / \mathrm{m}$ have been removed in order to avoid potential convergence problems during the FEA. An extrapolation gives a B-field to $600,000 \mathrm{~A} / \mathrm{m}$. The second curve stems from the manufacturer's catalogues and has been acquired using an Epstein frame. The B-field is measured for an $\mathrm{H}$-field between $0 \mathrm{~A} / \mathrm{m}$ and $10,000 \mathrm{~A} / \mathrm{m}$. Both curves are seen in Fig. 12 .

Fig.13 presents the results obtained from the FEA with both $\mathrm{BH}$ curves. $\mathrm{BH}(1)$ offers a better agreement with measurement output. The existence of high saturation zones makes it essential to have a BH characteristic measured for high $\mathrm{H}$-field values in order for the model to be realistic. These zones are mainly located in the stator. This study has therefore revealed the importance of material knowledge in an optimization 
process. A rough approximation of the $\mathrm{BH}$ curve definition has in fact introduced a $15 \%$ error on the no-load flux estimation.

The second material definition explored is the permanent magnet definition. In order to avoid remanence value uncertainty, a measurement has been conducted to determine the permanent magnet remanence: $B_{r}$ equals $1.2 T$. The magnetic field is measured in the air gap of a ring-shaped core using a Hall effect probe. As indicated in Fig.14, the finite element analysis provides good agreement with measurements whenever the magnetic remanence is well known. As a matter of fact, an uncertainty of approx. $B_{r}$ equal to $0.1 T$ prevents easily obtaining a realistic model (Fig.14). The difference between measurements and no-load flux calculations with FEA and $B r=1.1 T$ amounts to $10 \%$ at $\delta_{e x c}=-6 \mathrm{~A} / \mathrm{mm}^{2}$.

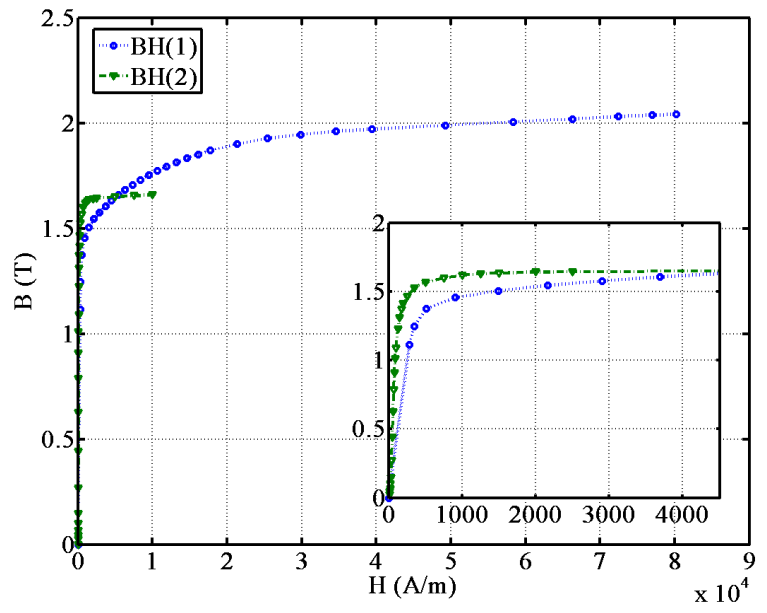

Fig. 12. Part of BH curves used in FEA

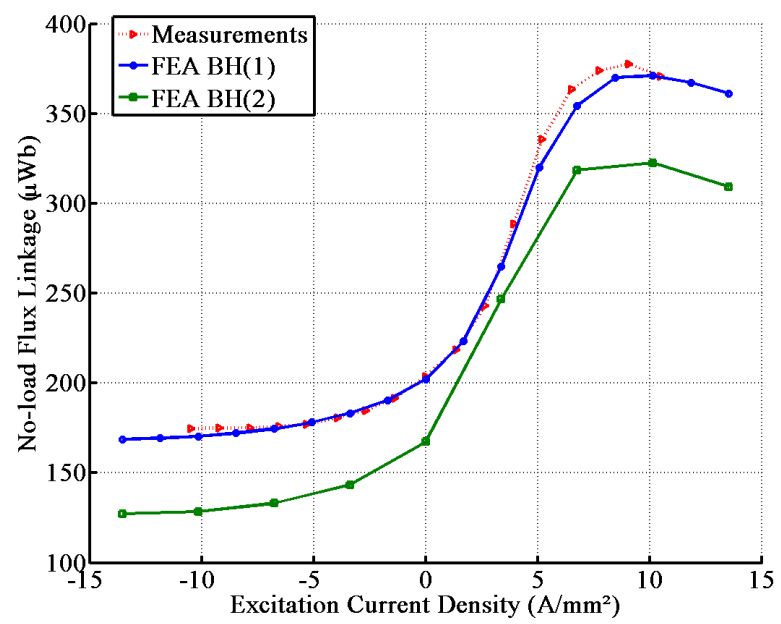

Fig. 13. FEA and measurements: No-load flux linkage vs. hybrid excitation current density, influence of the $\mathrm{BH}$ curve

b) Lamination: Three-dimensional finite element models allow taking lamination into account; in this machine, two elements are laminated, namely the rotor and the first part of

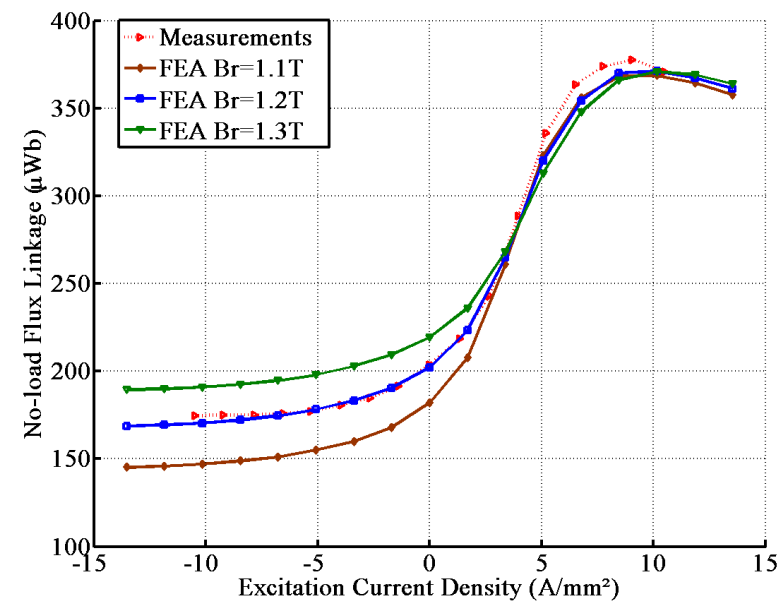

Fig. 14. FEA and measurements: No-load flux linkage vs. hybrid excitation current density, influence of $B_{r}$ value

the stator (2D). Two configurations have been explored with FEA, one without lamination the other with a stacking factor $\left(k_{\text {lam }}\right)$ equal to 0.97 (i.e. a realistic value). The stacking factor reflects the proportion of steel with respect to insulation. The major influence of lamination occurs for $\delta_{e x c} \leq 5 \mathrm{~A} / \mathrm{mm}^{2}$, as shown in Fig.15. Due to insulation, the no-load flux linkage decreases by $7 \%$.

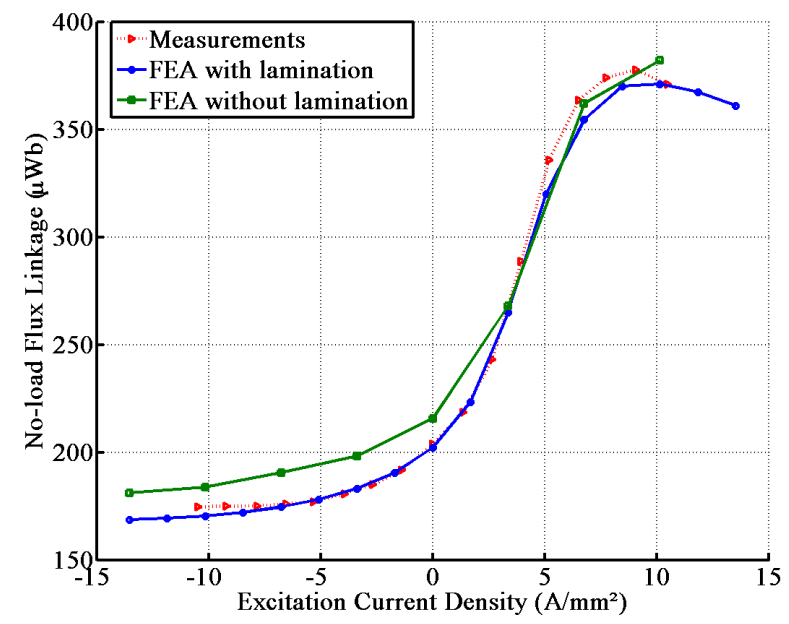

Fig. 15. FEA: No-load flux linkage vs. hybrid excitation current density, influence of lamination

\section{B. Electromotive force}

The electromagnetic performance of the prototype machine is predicted by a 3D finite element analysis and then compared with measurement results. Measurements and transient simulations are both conducted at a rotational speed of 1,500 $\mathrm{rpm}$. The back-EMF is obtained by numerically differentiating the flux linkage, as the following equation illustrates:

$$
e=-N_{r} \Omega \frac{d \Phi}{d \theta}
$$


where $\Omega$ is the angular speed of the rotor $\theta$ the angular position, $N_{r}$ the rotor pole number and $\Phi$ the flux-linkage of the phase windings. Fig. 16 compares the EMF obtained from measurements and simulations at a single excitation current density: the EMF simulated by FEA is indeed similar to measurement results.

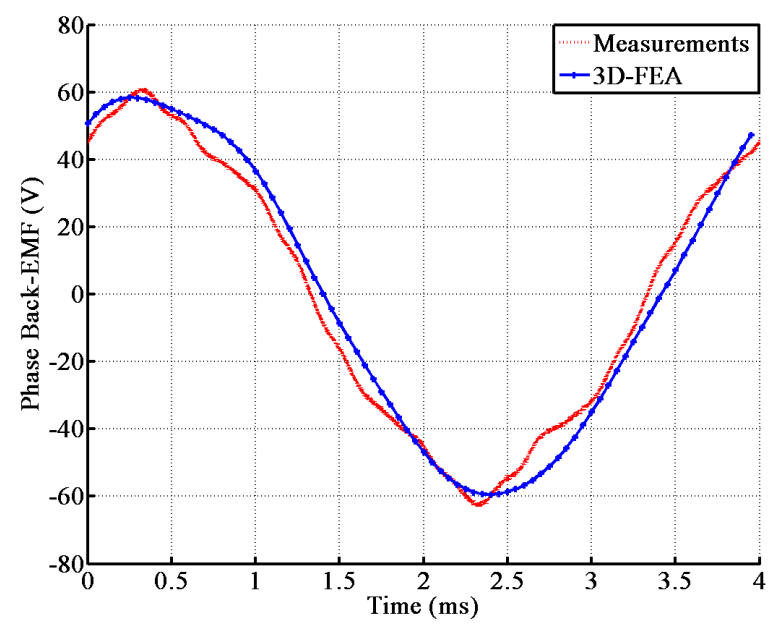

Fig. 16. FEA and measurements: Back EMF vs. Time

The back-EMF can be adjusted by the DC excitation current; moreover, as the flux linkage increases, a peak value appears at a high excitation current density (Fig.17).

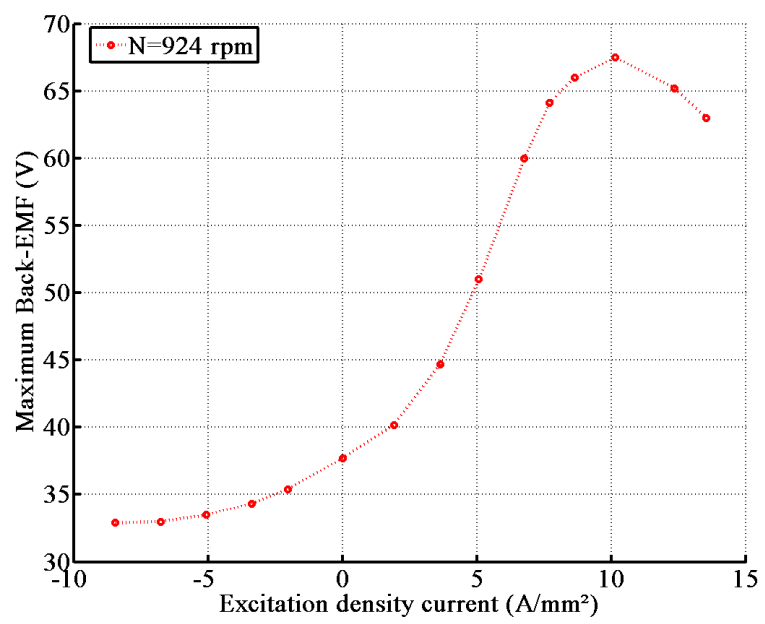

Fig. 17. Measurements: Maximum back-EMF vs. hybrid excitation current density

\section{3D FE ANALYSIS AND EXPERIMENTAL VALIDATION: LOAD TESTS}

In this part, the operating principle relative to load will be explored. The load calculation with FEM is time-consuming, so an analytical model has been implemented herein and then verified via a comparison between measurements and analytical results. To make use of this model, two hypotheses have been adopted: 1) permeability is assumed to be infinite without any saturation effect; and 2) the prototype is considered to be a smooth pole machine.

\section{A. Short-circuit current}

The short-circuit current density is determined in order to assess the potential of such a structure when in generator mode connected to a diode bridge rectifier (DBR). The maximum output power when the machine is connected to a DBR can actually be defined by the following formula [19]:

$$
P_{\max }=3 I_{c c} \frac{2}{\pi \sqrt{2}} U_{D C}
$$

where the DC-bus voltage $U_{D C}$ is assumed to be constant, and $I_{c c}$ is the mean short-circuit current. For measurement data, the experimental test bench used is the same as that displayed in Fig.9 with short-circuited armature windings. The short-circuit current is also determined by means of FEA and corresponds to the current that cancels the flux; in this case, only the fundamental part of the flux is being considered. To calculate this current, the $d$-axis position must first be determined. Next, three-phase currents, in phase opposition with the no-load flux, are injected. Lastly, the total excitation flux in the machine is computed and compared to zero. If the flux equals zero, then the short-circuit current density is obtained; otherwise, the current amplitude is increased until the fundamental flux component is cancelled.

Fig. 18 presents the evolution in short-circuit current density with respect to hybrid excitation current.

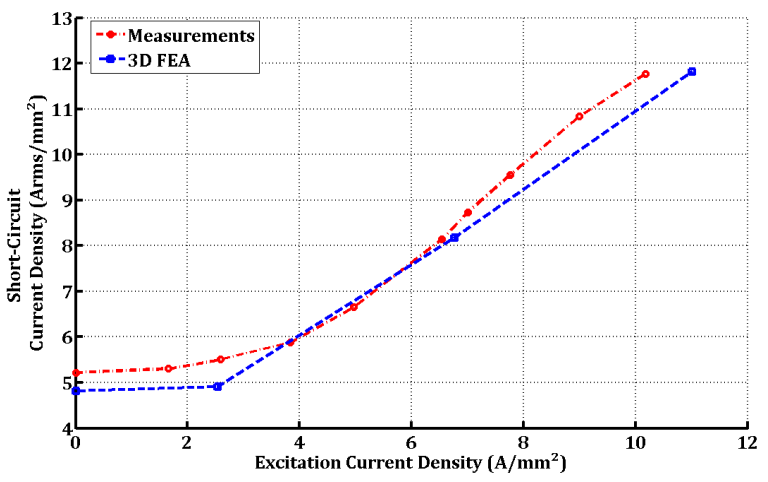

Fig. 18. FEA and experiments: Evolution of short-circuit current density vs. excitation current density

The FEA results are similar to measurement output even when harmonics are not taken into account. From Equation 2, for this structure in generator mode with a DBR connected to a $300 \mathrm{~V}$ DC-bus, the potential maximum power lies between $2,850 \mathrm{~W}$ and $5,800 \mathrm{~W}$.

\section{B. Output power measurements and comparison with calcu-} lation

For the configuration depicted in Fig.19 and Fig.20, the DBR is connected on the same DC-bus voltage supplying 


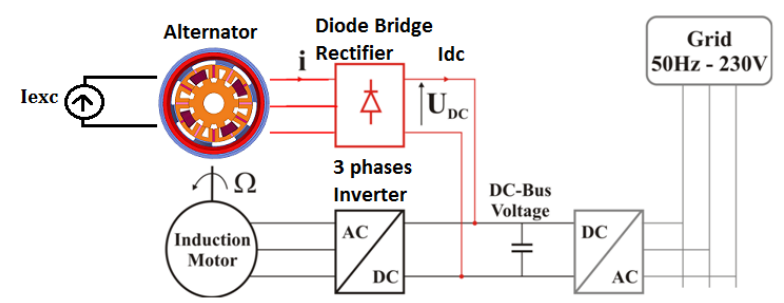

Fig. 19. Diagram of the experimental set-up (generator mode)

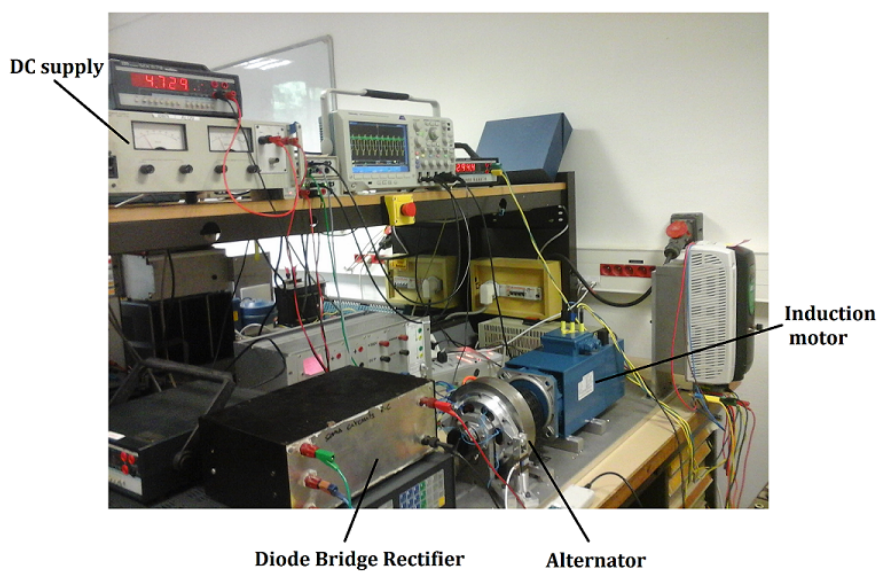

Fig. 20. Experimental test bench: The alternator is connected to both a DBR and a DC-bus

the 3-phase inverter that controls the induction motor; the alternator output power can be defined by (3):

$$
P_{D C}=U_{D C} I_{D C}
$$

Some assumptions have been adopted in order to calculate the alternator output power as a function of no-load flux linkage and short-circuit current. The armature coil resistances have been neglected $(R=0.7 \Omega)$. The DC-bus voltage remains equal to $300 \mathrm{~V}$. The phase-to-ground voltage can be decomposed into a Fourier series

$$
v_{A N}(t)=\sum_{k=1}^{+\infty} V_{2 k-1} \sin ((2 k-1) \omega t)
$$

The current is assumed to be $\mathrm{AC}$ and controls the opening and closing of switches. In addition, the current curve shape and magnitude is mainly given by the fundamental current (6):

$$
\begin{gathered}
i_{a}(t)=I_{n} \sin (\omega t)+\sum_{n=1}^{+\infty} I_{n} \sin (n \omega t) \\
i_{a}(t) \simeq I \sin (\omega t)
\end{gathered}
$$

Based on these assumptions, the machine can be described by Fig.21, with:

$$
e(t)=\Phi \omega \sin (\omega t+\delta)
$$

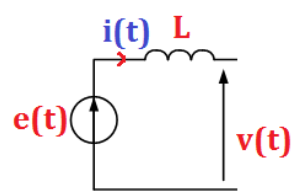

Fig. 21. Single-phase equivalent circuit

where $\Phi$ is the total flux-linkage, and $\delta$ the phase difference between $e$ and $v$. The circuit equation of the machine when operating as a generator is given by

$$
e(t)-L \frac{d i(t)}{d t}-v(t)=0
$$

In the sinusoidal steady state for each harmonic, this equation can be written using complex vectors, leading to a solution.[21] The DC current is determined by

$$
I_{D C}=\frac{3}{\pi} I
$$

And the DC power is:

$$
P_{D C}=\frac{3}{\pi} \frac{U_{D C}}{L} \sqrt{1-\left(\frac{2 U_{D C}}{\pi \Phi N_{r} \Omega}\right)^{2}}
$$

This equation 10 is only valid for

$$
\frac{2 U_{D C}}{\pi \Phi N_{r} \Omega} \leq 1
$$

with $N_{r}$ being the rotor pole number. The definition of a speed $\Omega_{b}$ (below this speed the output power equals to zero) thus appears as:

$$
\Omega_{b}=\frac{2 U_{D C}}{\pi \Phi N_{r}}
$$

Moreover, the short-circuit current $I_{c c}$ is defined by $\frac{\Phi}{L}$. This equation can thus be rewritten as follows:

$$
P_{D C}=\frac{3}{\pi} U_{D C} I_{c c} \sqrt{1-\left(\frac{\Omega_{b}}{\Omega}\right)^{2}}
$$

To verify the model, measurements have been recorded and compared to the calculation results. The no-load flux and short-circuit current values have been calculated with a 3DFEA. Output power was measured at various speeds for a single hybrid excitation current density $\left(7 \mathrm{~A} / \mathrm{mm}^{2}\right)$. Fig.22 presents a comparison between measured and model-based output power. These good results reveal that the model enables estimating the potential of a structure in generator mode more quickly than with a 3D-FEA combined with a circuit model. Measurements conducted in generator mode with the experimental test bench shown in Fig.19 and Fig.20 have made it possible to determine the copper, iron and mechanical losses. Copper losses in the armature and excitation circuits are known thanks to resistance and current values. Total copper losses vary between $85 \mathrm{~W}$ and $150 \mathrm{~W}$. Torque is measured using a torque sensor, while mechanical power can be deduced from both torque and speed values. The DC 


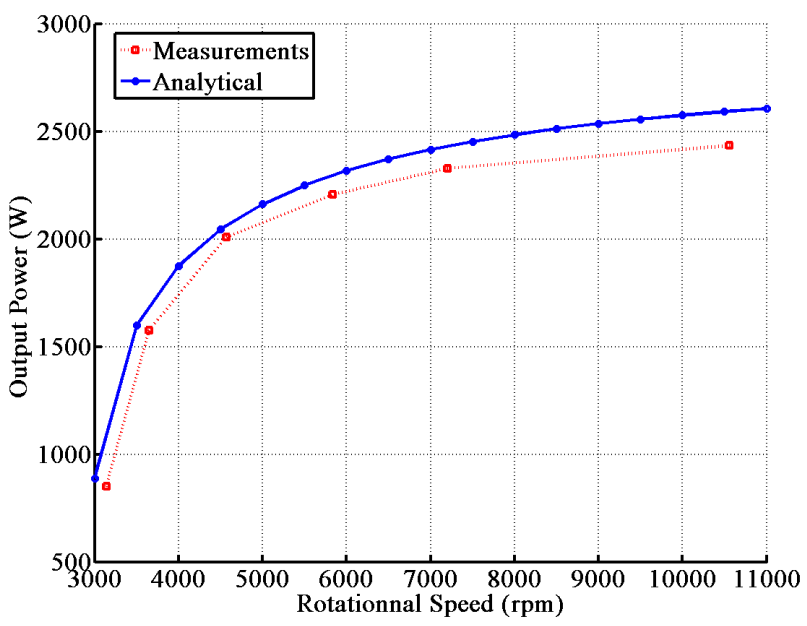

Fig. 22. Measurements and calculation: Output power vs. speed

current measurement allows proceeding with an output power calculation. The mechanical and iron losses are found by taking the differences between the mechanical power, copper losses and output power. Fig.23 displays output power and losses at various speeds for a single hybrid excitation density current $\left(7 \mathrm{~A} / \mathrm{mm}^{2}\right)$. Iron and mechanical losses are separated using a mechanical model [22]. As expected, iron losses increase with speed, and the mechanical losses vary between $0.68 \mathrm{~W}$ and $17.6 \mathrm{~W}$.

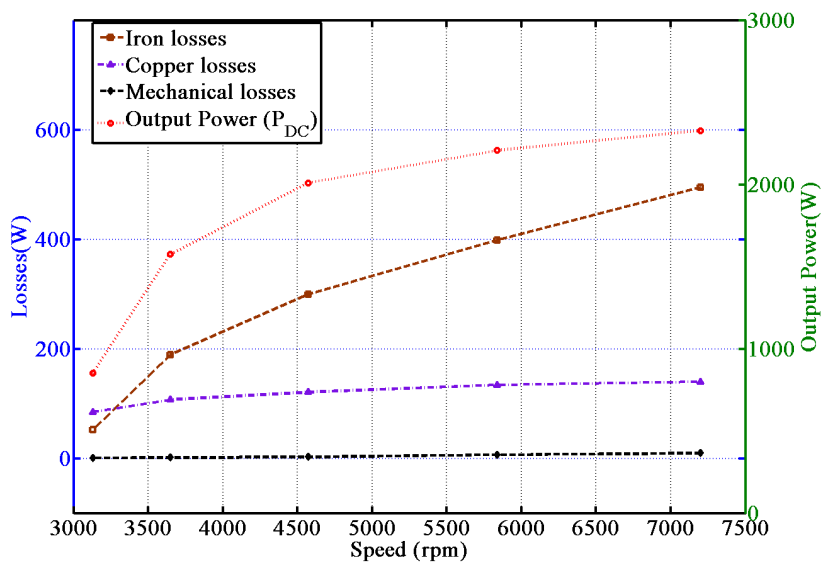

Fig. 23. Output power measurement and separation of losses by calculation and measurements

Flux density variations in the solid claw pole structure have been measured by a single-turn sense coil (Fig. 24). Eddy current losses in the yokes have been estimated. For example, at 7,200 rpm, iron losses due to induction variations equal 30 W, whereas total iron losses amount to $500 \mathrm{~W}$. Fig. 25 shows the flux measured in a claw pole. The portion of iron losses occurring in the solid claw pole structure is about $6 \%$ of the total iron losses.

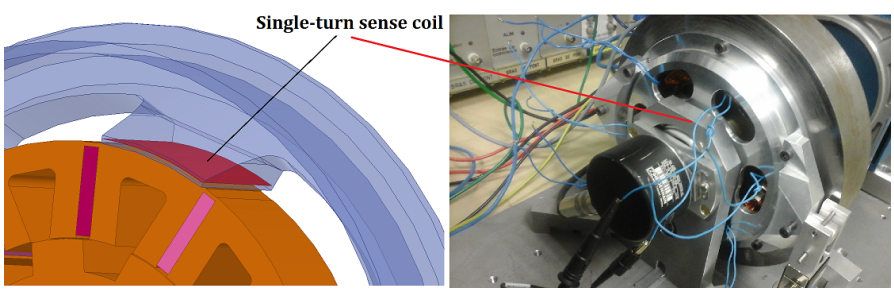

Fig. 24. FEM and prototype: Single-turn sense coil on a claw pole

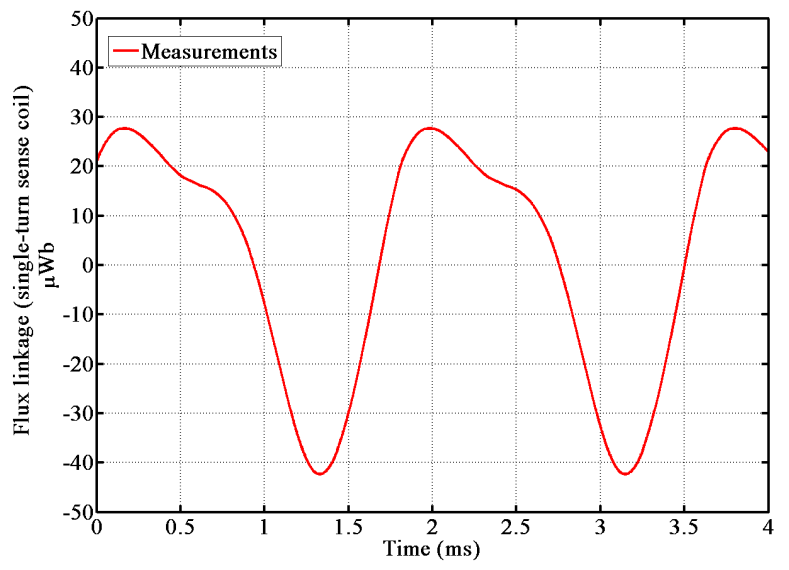

Fig. 25. Measurements: single-turn sense coil flux vs. Time

\section{CONCLUSiON}

This paper has presented one topology of a hybrid excited, flux-switching permanent magnet machine with claws located on the stator. Flux paths have been explored using a permanent magnet or else with hybrid excitation current in order to highlight axial flux paths. The investigation of noload flux linkage has shown remanence, lamination and BHcurve influences on the 3D-FE model. This 3D model offers a good level of agreement for both no-load flux linkage and electromotive force. The final part has presented prototype characteristics relative to the load. First, short-circuit currents have been computed to obtain an output power estimation. Second, output power has been measured and compared with calculation values. The model allows estimating output power of the structure when running in generator mode (with a DBR).

The operating principle of this new structure has been validated. The 3D FEA model developed in this paper has laid a foundation for the design optimization and further research on prototype performance.

\section{REFERENCES}

[1] Zhao, C. and Yan, Y., "A Review of Development of Hybrid Excitation Synchronous Machine", Proceedings of the IEEE International Symposium on Industrial Electronics, pp. 857-862, 2005

[2] Owen, R. and Zhu, Z.Q. and Wang, J.B. and Stone, D.A. and Urquhart, I., "Review of variable-flux permanent magnet machines", International Conference on Electrical Machines and Systems, pp. 1-6, 2011

[3] Lipo, T.A., "A novel permanent magnet motor with doubly salient structure", IEEE Transactions on Industry Applications, pp. 1069-1078, 1995 
[4] Rauch, S.E. and Johnson, L.J., "Design Principles of Flux-Switch Alternators ", Transactions of the American Institute of Electrical Engineers. Part III : Power Apparatus and Systems, pp.1261-1268, 1955

[5] Zhu, Z.Q. and Chen, J.T., "Advanced Flux-Switching Permanent Magnet Brushless Machines", IEEE Transactions on Magnetics, pp. 1447-1453, 2010

[6] Wang, Y. and Deng, Z., "Comparison of Hybrid Excitation Topologies for Flux-Switching Machines”, IEEE Transactions on Magnetics, pp. 25182527, 2012

[7] Owen, R. L. Zhu, Z. Q. and Jewell, G. W., "Hybrid-Excited FluxSwitching Permanent-Magnet Machines With Iron Flux Bridges", IEEE Transactions on Magnetics, pp. 1726-1729, 2010

[8] Fu, X. and Zou, J., "Numerical Analysis on the Magnetic Field of Hybrid Exciting Synchronous Generator", IEEE Transactions on Magnetics, 4590-4593, 2009

[9] Hoang, E. Lécrivain, M.and Gabsi, M.," A new structure of a switching flux synchronous polyphased machine with hybrid excitation", EPE, pp $1-8,2007$

[10] Liu, X. and Zheng, A. and Wang, C., "A Stator-Separated Axial Flux-Switching Hybrid Excitation Synchronous Machine", Journal of international Conference on Electrical Machines and Systems, Vol. 1, No. 4, pp. 399-404, 2012

[11] Laldin, O. and Sudhoff, S.D. and Pekarek, S., "Analysis and Design of Axial Hybrid Synchronous Machines", ICEM International Conference on Electrical Machines, pp. 2593-2599, 2014

[12] Borocci, G. and Capponi, F.G. and De Donato, G. and Caricchi, F., "Mixed-Pole Hybrid-Excitation Machine", ICEM International Conference on Electrical Machines, pp. 1-7, 2014

[13] Syverson, C.D. and Mankato, N. and Cums, W. R., "Hybrid Alternator", US Patent, March 14, 1996

[14] Liu, X. and Lin, H. and Zhu, Z.Q. and Yang, C. Fang, S. and Guo J.,
“ A Novel Dual-Stator Hybrid Excited Synchronous Wind Generator", IEEE Transactions on Industry Applications, pp. 947-953, 2009

[15] Capponi, F.G. and De Donato, G. and Borocci, G. and F. Caricchi, "Axial-Flux Hybrid-Excitation Synchronous Machine: Analysis, Design and Experimental Evaluation", IEEE Transactions on Industry Applications, vol.50, no.5, pp.3173-3184, 2014

[16] Zhang Z. and Ma, S. and Dai, J. and Yan Y., "Investigation of Hybrid Excitation Synchronous Machines With Axial Auxiliary Air-Gaps and Non-Uniform Air-Gaps", IEEE Transactions on Industry Applications, pp. 1729-1737, 2014

[17] Zhang, Z. and Yan, Y. and Yang, S. and Bo, Z., "Principle of Operation and Feature Investigation of a New Topology of Hybrid Excitation Synchronous Machine", IEEE Transactions on Magnetics, pp. 2174 2180, 2008

[18] Yildiriz, E. and Onbilgin, G., "Design studies of Axial Flux Hybrid Excitation Synchronous Machine with magnetic bridge", 8th International Conference on Electrical and Electronics Engineering (ELECO), pp. 234 237, 2013

[19] Gaussens, B. Hoang, E. Manfé, P. Lécrivain, M. and Gabsi, M., "Improved Output Power Capability of Hybrid Excited Flux-Switching DCAlternators : Analysis and Experiments", Industrial Technology (ICIT), pp.960-965, 2012

[20] Hoang, E. Lécrivain, M.and Gabsi, M.," Flux Switching Dual Excitation Electrical Machine”, US Patent, March 8, 2007

[21] Caliskan, V., Perreault, D. J., Jahns, T. M., Kassakian, J. G. , “Analysis of three-phase rectifiers with constant-voltage loads", Circuits and Systems I: Fundamental Theory and Applications IEEE Transactions on, 2003

[22] Vrancik, J. , "Prediction of windage power loss in alternators", $R$ TN D-4849, NASA, 1968 